\title{
PENGEMBANGAN BUKU AJAR APLIKASI MATEMATIKA MENGGUNAKAN PENDEKATAN REACT
}

\author{
Alfiani Athma Putri Rosyadi ${ }^{1}$ \\ ${ }^{1}$ Program Studi Pendidikan Matematika FKIP Universitas Muhammadiyah Malang \\ Email : ${ }^{1}$ Alfi_rosyadi@umm.ac.id
}

\begin{abstract}
Abstrak
Pembelajaran yang ada dilengkapi dengan buku ajar diharapkan dapat menyampaikan konsep yang ada dalam materi. Buku ajar yang disusun menggunakan pendekatan REACT (Relating, Eksperiencing, Applying, Cooperating dan Transferring). Pendekatan REACT dipilih karena fakta yang muncul di lapangan buku ajar yang disusun belum mengkaitkan dengan kegiatan sehari-hari, melibatkan aktivitas mahasiswa dan menyusun tugas proyek. Pengembangan buku ajar dengan Aplikasi Matematika dengan pendekatan REACT melalui tahapan : a) analisis pendahuluan, b) penyusunan buku ajar, c) validasi dan revisi, dan d) menghasilkan produk buku ajar. Dalam proses analisis pendahuluan terdapat proses mengkaji kurikulum dan materi yang terkait, selanjutnya disusun buku ajar yang di dalamnya terdapat : Tujuan Pembelajaran, Materi, Kegiatan Pembelajaran, Perangkat Evaluasi dan kelengkapan buku ajar. Berikutnya adalah tahap validasi dan revisi, di dalamnya terdapat proses validasi oleh ahli dan perbaikan buku ajar sesuai dengan hasil validasi. Langkah terakhir yaitu produk buku ajar yang sudah direvisi dan siap untuk dicetak. Saran untuk peneliti berikutnya adalah perlunya penambahan soal-soal dan dilengkapi dengan jawaban terkait dengan isi dalam buku ajar. Selain itu juga bisa ditambahkan dengan penambahan kajian tentang riset yang mendukung dalam setiap bab untuk menambah referensi mahasiswa.
\end{abstract}

Kata kunci: buku ajar, RECT, pengembangan

\begin{abstract}
Existing learning equipped with textbooks is expected to convey the concepts contained in the material. Textbooks are prepared using the REACT approach (Relating, Experiencing, Applying, Cooperating and Transferring). The REACT approach was chosen because the facts that appeared in the field of textbooks that had been compiled had not yet linked daily activities, involved student activities and compiled project tasks. Development of textbooks with Mathematics Applications with REACT approach through stages: a) preliminary analysis, b) preparation of textbooks, c) validation and revision, and d) producing textbook products. In the preliminary analysis process there is a process of reviewing the curriculum and related material, then a textbook is prepared which includes: Learning Objectives, Materials, Learning Activities, Evaluation Tools and completeness of textbooks. Next is the stage of validation and revision, in which there is a validation process by experts and improvement of textbooks according to the results of validation. The final step is the textbook product that has been revised and is ready to be printed. Suggestions for the next researcher are the need to add questions and be equipped with answers related to the contents in the textbook. In addition, it can also be added to the addition of studies on supporting research in each chapter to add student references.
\end{abstract}

Keywords: textbooks, RECT, development 


\section{PENDAHULUAN}

Pembelajaran matematika di perguruan tinggi dipengaruhi oleh dua faktor antara lain yaitu: faktor internal dan eksternal. Faktor internal terdiri dari persiapan mahasiswa sebelum proses pembelajaran dan kesiapan mahasiswa selama proses pembelajaran. Faktor eksternal terdiri dari: perangkat pembelajaran, metode pembelajaran dan sumber belajar yang dipillih. Perangkat pembelajaran memuat RPP, Tes, lembar observasi, wawancara dll.

Sumber belajar dan media pembelajaran yang dipilih disesuaikan dengan karakteristik mahasiswa yang ada di dalam kelas. Bentuk media pembelajaran yang digunakan bisa bervariasi, mulai dari audio, visual, dan audio visual. Salah satu bentuk dari media pembelajaran yang berbentuk audio yaitu buku ajar. Buku ajar adalah buku yang digunakan dalam proses pembelajaran yang dibuat oleh ahli yang disesuaikan dengan tujuan yang dicapai (Bart, 2015).

Pembelajaran yang ada dilengkapi dengan buku ajar diharapkan dapat menyampaikan konsep yang ada dalam materi. Buku ajar yang disusun menggunakan pendekatan REACT (Relating, Eksperiencing, Applying, Cooperating dan Transferring). Pendekatan REACT dipilih karena fakta yang muncul di lapangan buku ajar yang disusun belum mengkaitkan dengan kegiatan sehari-hari, melibatkan aktivitas mahasiswa dan menyusun tugas proyek (Halimatusadiah dkk: 2017). Selain itu menurut Ibrahim (2018), dengan menggunakan REACT dapat meningkatkan kepercayaan diri mahasiswa dalam kegiatan pembelajaran. Hal ini dikarenakan pada langkah-langkah REACT, mahasiswa diminta untuk selalu berperan aktif baik secara individu maupun kelompok (Herawati, 2016).

Materi yang dipilih yaitu aplikasi matematika. Dalam buku ajar yang dikembangkan ini disesuaikan dengan karakteristik dan kebutuhan mahasiswa agar proses pembelajaran dapat berjalan sesuai dengan tujuan yang diharapkan (Tegeh, 2015). Di dalam buku ini terdapat konsep yang membahas tentang : (1) Fungsi Gamma, (2) Fungsi Beta dan Integral Diriclet, (3) Fungsi Kesalahan, Integral Eksponensial, Integral Sinus Frensel dan Integral Cosinus Frensel, (4) Fungsi Bessel dan (5) Fungsi Legendre (Rosyadi, 2016). Fokus yang ada pada penelitian ini yaitu Fungsi Gamma, Fungsi Beta dan Fungsi Bessel.

Pendekatan REACT pada buku ajar memiliki beberapa tujuan yaitu: peningkatan kemampuan pemecahan masalah, peningkatan pemahaman mahasiswa, kemampuan berpikir kritis dan kemampuan kerjasama (Lestari, 2017; Sugiarti, 2018; Wulandari, 2015).

\section{METODE}

Penelitian ini merupakan Research and Development karena di dalamnya terdapat prosedur pengembangan buku ajar aplikasi matematika dan proses analisis (Rosyadi, 2016). Subjek penelitian adalah sepuluh mahasiswa prodi pendidikan Matematika di Malang minimal semester 6. Hal ini dikarenakan buku ajar aplikasi matematika ini dipelajari setelah mahasiswa menempuh matakuliah matematika murni yang ada pada semester 1 sampai 6 .

Jenis data dalam pengembangan buku ajar ini adalah data kualitatif dan kuantitatif.

a. Data kualitatif. Pada uji coba tahap pertama data kualitatif berasal dari kritik, saran dan komentar dari subyek uji coba terhadap buku ajar. Sedangkan pada uji coba tahap kedua data kualitatif berasal dari jawaban subyek coba pada saat wawancara dan saat memahami buku ajar.

b. Data kuantitatif. Berupa poin penilaian yang diberikan oleh subyek uji coba tahap pertama dan kedua terhadap buku ajar sesuai dengan kriteria penilaian yang diberikan. 
Penelitian ini dilakukan dengan menggunakan langkah-langkah berikut

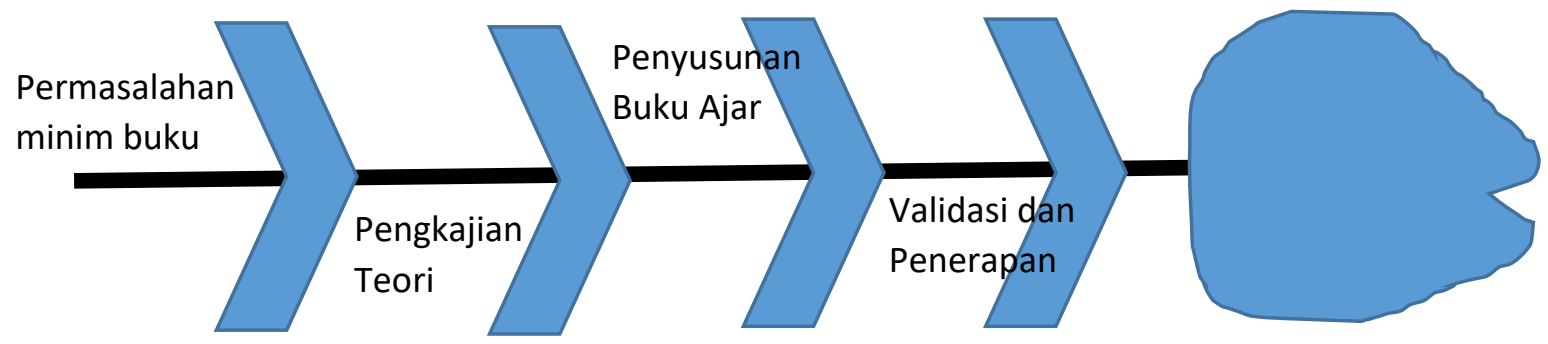

\section{Gambar 1. Fish Bone}

Validasi instrument dilakukan validator yaitu dua orang dosen matematika UMM. Instrumen yang divalidasi yaitu: buku ajar, angket dan wawancara. Hal ini dilakukan agar dapat mengetahui bagaimana kevalidan dari buku ajar yang sudah disusun.

Angket diberikan kepada mahasiswa yang sudah memahami buku ajar yang sudah disusun. Hal ini dilakukan agar dapat diketahui bagaiman son mahasiswa terhadap buku ajar yang sudah disusun. Wawancara yang dilakukan untuk mengetahui informasi secara mendalam terkait dengan bagaimana respon dan kendala yang dialami mahasiswa. Subjek penelitian yang diambil yaitu tiga orang mahasiswa dengan kemampuan tinggi, sedang dan rendah yang dianggap mewakili keseluruhan mahasiswa.

Berikut adalah skema kegiatan penelitian yang dilakukan

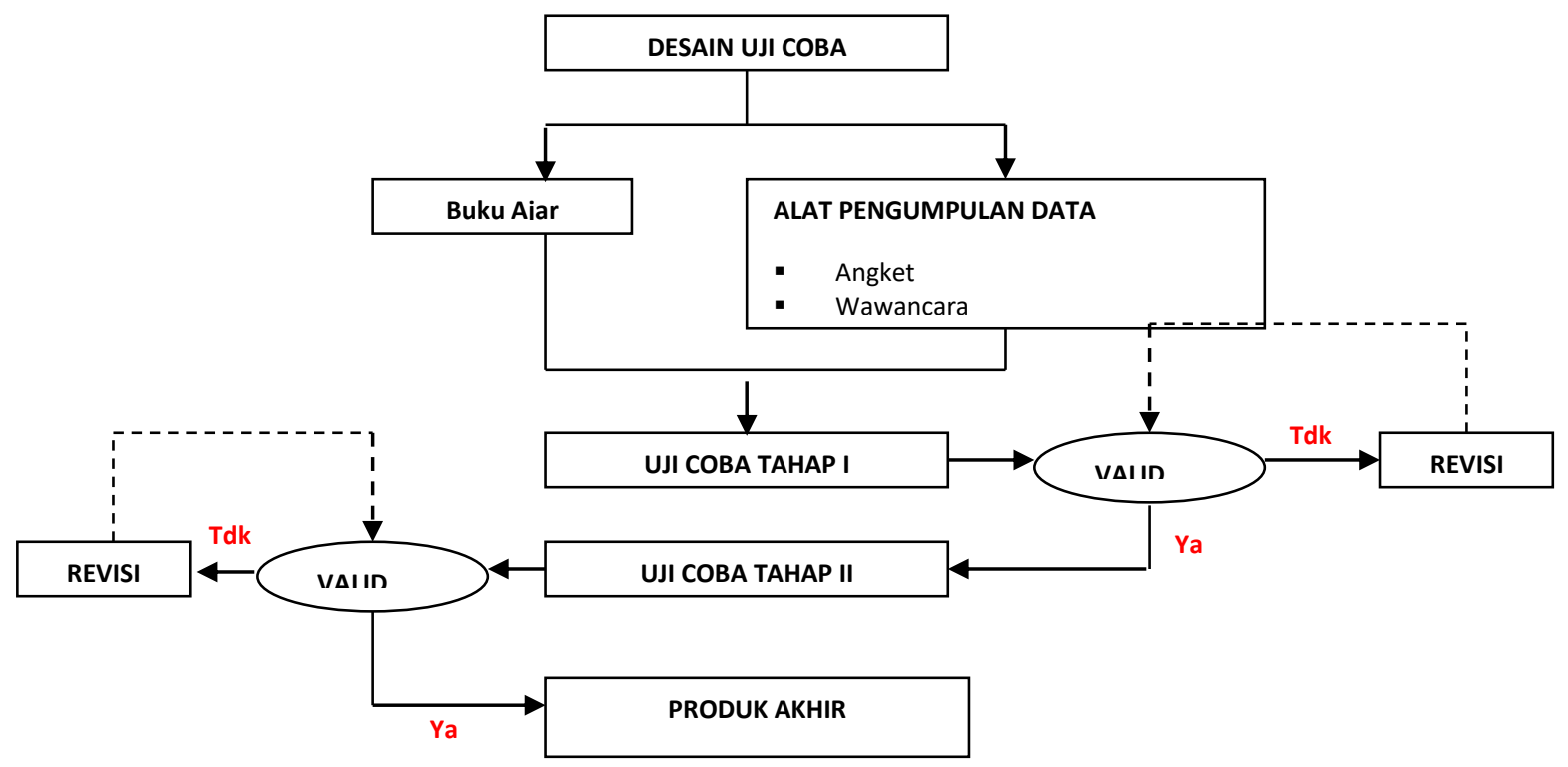

Gambar 2. Skema penelitian 


\section{HASIL DAN PEMBAHASAN}

Pengembangan buku ajar dengan Aplikasi Matematika dengan pendekatan REACT melalui tahapan : a) analisis pendahuluan, b) penyusunan buku ajar, c) validasi dan revisi, dan d) menghasilkan produk buku ajar. Berikut ini adalah penjelasan dari setiap tahapan.

a. Analisis Pendahuluan

Proses analisis pendahuluan terdapat analisis kurikulum yang digunakan dan materi yang dibahas.

Standar Kompetensi

Deskripsi Mata Kuliah

:Setelah mengikuti matakuliah ini mahasiswa diharapkan dapat memahami fungsi-fungsi khusus dan terampil memecahkan masalah terapan.

:Mata kuliah ini membahas tentang : (1) Fungsi Gamma, (2) Fungsi

Beta dan Integral Diriclet, (3) Fungsi Kesalahan, Integral Eksponensial, Integral Sinus Frensel dan Integral Cosinus Frensel, (4) Fungsi Bessel, (5) Fungsi Legendre.

b. Penyusunan Buku Ajar

Pada setiap materi pada buku ini terdapat skema keterkaitan, materi prasyarat, aktivitas yang harus diselesaikan mahasiswa, definisi, teorema, tugas proyek, rangkuman dan latihan soal. Materi yang dibahas adalah fungsi, fungsi Gamma, fungsi Beta, dan fungsi Bessel. Fungsi Gamma dan fungsi Beta terbahas juga pada matakuliah statistika matematika sehingga mahasiswa dapat membuat korelasi antara kedua matakuliah tersebut atau mungkin dengan matakuliah lain. Selain itu, sebelum memulai bab awal mahasiswa diingatkan kembali tentang materi yang harus dikuasai.

Setiap awal materi dibahas tentang pengkaitan dengan aplikasi dalam kehidupan sehari-hari dan materi yang terkait. Hal ini dilakukan agar mahasiswa bisa tertarik dan lebih memahami materi.

c. Validasi dan revisi

Hasil validasi diperoleh dari penilaian subyek coba pada uji coba tahap pertama terhadap buku ajar yang telah disusun. Subyek coba terdiri dari 2 orang yaitu dua orang dosen matematika Universitas Muhammadiyah Malang. Berdasarkan sajian hasil validasi penjelasan hasil validasi tiap aspek antara lain:

1. Kejelasan isi tujuan pembelajaran

Penilaian untuk aspek kejelasan materi isi tujuan pembelajaran ini memiliki nilai rata-rata 3,67. Hal ini berarti aspek kejelasan isi tujuan pembelajaran yang disusun valid dan tidak perlu revisi

2. Kesesuaian materi dengan tujuan pembelajaran

Penilaian untuk aspek kesesuaian materi dengan tujuan pembelajaran ini memiliki nilai ratarata 3,33. Hal ini berarti aspek kesesuaian materi dengan tujuan pembelajaran yang disusun valid dan tidak perlu revisi

3. Kebenaran materi meliputi konsep, simbol, contoh dan ilustrasi

Penilaian untuk aspek kebenaran materi meliputi konsep, simbol, contoh dan ilustrasi ini memiliki nilai rata-rata 3 . Hal ini berarti aspek kebenaran materi meliputi konsep, simbol, contoh dan ilustrasi cukup valid dan tidak perlu revisi.

4. Sistematika penyusunan materi

Penilaian untuk aspek sistematika penyusunan materi ini memiliki nilai rata-rata 3,67. Hal ini berarti aspek sistematika penyusunan materi valid dan tidak perlu revisi.

5. Ketepatan masalah kontekstual, meliputi:

a) Relating, memiliki nilai rata-rata 3,33. Hal ini berarti aspek ketepatan masalah kontekstual yaitu relating valid dan tidak perlu revisi.

b) Experiencing, memiliki nilai rata-rata 3,17. Hal ini berarti aspek ketepatan masalah kontekstual yaitu experiencing cukup valid dan tidak perlu revisi. 
c) Applying, memiliki nilai rata-rata 3,33. Hal ini berarti aspek ketepatan masalah kontekstual yaitu applying valid dan tidak perlu revisi.

d) Cooperating, memiliki nilai rata-rata 3,5. Hal ini berarti aspek ketepatan masalah kontekstual yaitu cooperating valid dan tidak perlu revisi

e) Transferring, memiliki nilai rata-rata 3,33. Hal ini berarti aspek ketepatan masalah kontekstual yaitu transferring valid dan tidak perlu revisi

d. Produk buku ajar

Buku ajar ini dihasilkan setelah memperbaiki hasil revisi dari validator. Berdasarkan hasil angket mahasiswa diperoleh data bahwa mahasiswa dapat memahami dengan baik dan ada masukan terkait dengan ditambahkan contoh soal dan pembahasan pada beberapa bab (Ismawati, 2017). Produk buku ajar yang dihasilkan sesuai dengan langkah-langkah yang sudah ditetapkan dan dapat digunakan oleh mahasiswa karena sudah melalui uji coba pada ahli dan mahasiswa kelompok kecil (Maharani, 2017). Berdasarkan hasil angket yang diisi mahasiswa dapat dilihat bahwa Pengembangan buku ajar aplikasi matematika dengan pendekatan REACT dapat menumbuhkan kerjasama dan kemampuan berpikir kritis (Wulandari, 2015). Sejaln dengan pendapat Sili (2018), Santoso (2017) dan Herawati (2016), pemahaman mahasiswa juga menjadi lebih baik karena mereka terlibat langsung dalam proses pembelajaran.

\section{KESIMPULAN DAN SARAN}

Pengembangan buku ajar dengan Aplikasi Matematika dengan pendekatan REACT melalui tahapan : a) analisis pendahuluan, b) penyusunan buku ajar, c) validasi dan revisi, dan d) menghasilkan produk buku ajar. Dalam proses analisis pendahuluan terdapat proses mengkaji kurikulum dan materi yang terkait, selanjutnya disusun buku ajar yang di dalamnya terdapat : Tujuan Pembelajaran, Materi, Kegiatan Pembelajaran, Perangkat Evaluasi dan kelengkapan buku ajar. Berikutnya adalah tahap validasi dan revisi, di dalamnya terdapat proses validasi oleh ahli dan perbaikan buku ajar sesuai dengan hasil validasi. Langkah terakhir yaitu produk buku ajar yang sudah direvisi dan siap untuk dicetak.

Saran untuk peneliti berikutnya adalah perlunya penambahan soal-soal dan dilengkapi dengan jawaban terkait dengan isi dalam buku ajar. Selain itu juga bisa ditambahkan dengan penambahan kajian tentang riset yang mendukung dalam setiap bab untuk menambah referensi mahasiswa.

\section{DAFTAR RUJUKAN}

Bart, W. M., Hokanson, B., Sahin, I., \& Abdelhady, M. (2015). An investigation of the gender differences in creative thinking abilities among 8th and $11^{\text {th }}$ grade students. Thinking Skills and Creativity, 17, 17-24

Halimatusadiah, A. M. A., Maulana, M., \& Syahid, A. A. (2017). Pengaruh Pendekatan Kontekstual Berstrategi React Terhadap Kemampuan Pemahaman Matematis Dan Motivasi Belajar Siswa Pada Operasi Bilangan Bulat. Jurnal Pena Ilmiah, 2(1), 791-800.

Ibrahim, M. (2018). Peningkatan Kepercayaan Diri Siswa Terhadap Matematika Dengan Menggunakan Pendekatan CTL (React). Jurnal Tatsqif, 16(1), 55-77.

Herawati, L. (2016). Pembelajaran melalui strategi REACT untuk meningkatkan kemampuan pemahaman matematis siswa sekolah menengah kejuruan. JP3M (Jurnal Penelitian Pendidikan dan Pengajaran Matematika), 2(1), 35-40.

Ismawati, R. (2017). Strategi React dalam Pembelajaran Kimia SMA. Indonesian Journal of Science and Education, 1(1), 1-7.

Lestari, W. (2017). Efektivitas Model Pembelajaran React Dengan Pendekatan Rme Terhadap Kemampuan Pemecahan Masalah Matematis Pada Materi Bangun Ruang Kelas Viii Smp Ma’arif Nu Paguyangan. Doctoral dissertation, Universitas Peradaban. 
Maharani, S., \& Andari, T. (2017). Pengembangan Buku Ajar Aljabar Linear Untuk Mahasiswa Pendidikan Matematika Berbasis Model Discovery-Inquiry. In Prosiding Seminar Nasional Hasil Penelitian LPPM Universitas PGRI Madiun (pp. 148-152).

Rosyadi, A. A. P. (2016). Kalkulus untuk Teknik. Malang: CV Ampuh Multi Rejeki.

Rosyadi, A. A. P. (2016). Metodologi Penelitian. Malang: UMM Press.

Santoso, A. B., Soleh, D. R., \& Winarsih, E. (2017). PENGEMBANGAN BUKU AJAR MKU BAHASA INDONESIA BERBASIS KARAKTER BAGI MAHASISWA IKIP PGRI MADIUN. In Prosiding Seminar Nasional Hasil Penelitian LPPM Universitas PGRI Madiun (pp. 242-248).

Sugiarti, W., Taufik, M., Rosyadi, A. A. P., Khusna, A. H., \& Azmi, R. D. (2018). Pembelajaran Berbasis REACT untuk Meningkatkan Pemahaman Siswa Kelas X pada Materi Fungsi Eksponensial di SMAN 2 Batu. Inspiramatika, 4(2), 112-119.

Sili, K. K., Napfiah, S., \& Kurniawati, A. (2018). Pengembangan Modul Materi Barisan dan Deret Kelas X SMK dengan Pendekatan REACT. PRISMATIKA (Jurnal Pendidikan dan Riset Matematika), 1(1), 1022.

Tegeh, I. M., Jampel, I. N., \& Pudjawan, K. (2015). Pengembangan Buku Ajar Model Penelitian Pengembangan dengan model ADDIE. In Seminar Nasional Riset Inovatif, 3.

Wulandari, N. C., Dwijanto, D., \& Sunarmi, S. (2015). Pembelajaran Model REACT Dengan Pendekatan Saintifik Terhadap Kemampuan Berpikir Kritis dan Kerjasama. Unnes Journal of Mathematics Education, 4(3). 